\title{
Independent effects of HIV infection and cocaine dependence on neurocognitive impairment in a community sample living in the Southern United States
}

\author{
Christina S. Meade ${ }^{a}$, Sheri L. Towe ${ }^{a}$, Linda M. Skalski ${ }^{b}$, and Kevin R. Robertson ${ }^{c}$ \\ a Duke University School of Medicine, Department of Psychiatry and Behavioral Sciences and \\ Duke Global Health Institute, Box 90519, Durham, NC, 27708, USA \\ b Duke University, Department of Psychology and Neuroscience, Box 90086, Durham, NC, \\ 27708, USA \\ c University of North Carolina at Chapel Hill, Department of Neurology, Physicians Office Building, \\ 170 Manning Drive, Chapel Hill, NC, 27599, USA
}

\begin{abstract}
Background-Prior studies have established that methamphetamine and HIV can have additive deleterious effects on neurocognitive functioning, but there has been relatively little research on other stimulants like cocaine. This study investigated the effects of cocaine and HIV on neurocognitive impairment in a large, well-characterized sample.
\end{abstract}

Methods-The sample included 193 adults across four groups: HIV-positive cocaine users $(\mathrm{n}=48)$, HIV-negative cocaine users ( $\mathrm{n}=53)$, HIV-positive non-drug users $(\mathrm{n}=60)$, and HIVnegative non-drug users $(n=32)$. Cocaine users met criteria for lifetime dependence and had pastmonth cocaine use. A comprehensive battery assessed substance abuse and neurocognitive functioning.

Results-Participants were mostly male (66\%) and African-American (85\%), with a mean age of 46.09 years. The rate of global impairment was 33\%, with no significant main effects across groups on likelihood of impairment. There were main effects for cocaine on processing speed and executive functioning, with cocaine users having greater impairment $(\mathrm{F}=9.33$ and $\mathrm{F}=4.22$, respectively), and for HIV on attention, with HIV-infected persons having greater impairment

(C) 2015 Published by Elsevier Ltd.

Corresponding author: Christina S. Meade Duke University Box 90519 Durham, NC 27708 USA christina.meade@ duke.edu tel. 919-613-6549 fax. 919-613-6215.

Publisher's Disclaimer: This is a PDF file of an unedited manuscript that has been accepted for publication. As a service to our customers we are providing this early version of the manuscript. The manuscript will undergo copyediting, typesetting, and review of the resulting proof before it is published in its final citable form. Please note that during the production process errors may be discovered which could affect the content, and all legal disclaimers that apply to the journal pertain.

Contributors

Meade designed the original project and secured grant funding; Meade, Robertson, Towe, and Skalski conceptualized the current study; Meade and Towe conducted the analyses; Meade drafted the manuscript, and Towe and Skalski wrote additional sections; and all authors contributed to and have approved the final manuscript.

Conflict of Interest

No conflict declared. 
$(\mathrm{F}=5.55)$. There was an interaction effect for executive functioning, with the three patient groups having greater impairment than controls $(\mathrm{F}=5.05)$. Nonparametric analyses revealed significant additive impairment in the presence of both HIV and cocaine for processing speed.

Conclusions-While cocaine does not appear to increase vulnerability to global HIV-associated neurocognitive impairment, it does have independent adverse effects on executive functioning and processing speed. Given prior evidence that domain-specific deficits predict real-world impairments, our results may help explain the poorer behavioral and functional outcomes observed in HIV-infected cocaine users.

\section{Keywords}

HIV/AIDS; cocaine dependence; drug abuse; neurocognitive impairment; HIV-associated neurocognitive disorders; neuropsychology

\section{INTRODUCTION}

Drug abuse, particularly the use of stimulants such as cocaine and methamphetamine, is disproportionately prevalent in HIV-infected persons (Bing et al., 2001; Garin Escriva et al., 2014; Mimiaga et al., 2013; Pence et al., 2008; Siconolfi et al., 2013). In a recent study of $>3,000$ patients receiving HIV care in four United States (US) cities, 9.0\% used amphetamines and $8.5 \%$ used crack-cocaine in the past 3 months (Mimiaga et al., 2013). In the only nationally representative sample of adults receiving HIV care in the US, approximately half reported illicit drug use in the past year, and a quarter of these drug users met criteria for current dependence (Bing et al., 2001). In the South, where nearly half of new HIV infections are occurring (Reif et al., 2013), cocaine remains the greatest drug burden, with its societal impact exceeding that of any other region (US Department of Justice, 2011).

Within days of infection, HIV can infiltrate the central nervous system, causing direct and indirect damage to brain structure and functioning (Valcour et al., 2011). If untreated, HIV patients may experience severe cognitive impairments, including dementia (Sacktor, 2002). Since the introduction of antiretroviral therapy (ART), milder cognitive disorders are more common (Antinori et al., 2007; Brew and Gonzalez-Scarano, 2007). The CHARTER study, a large multi-site study in the US that enrolled >1,500 persons between 2003 and 2007, reported a $52 \%$ prevalence of HIV-associated neurocognitive impairment, most prominently in learning, memory, attention, and executive functioning (Heaton et al., 2010, 2011). Neurocognitive impairment is most prevalent among patients with advanced HIV disease, including low nadir CD4 cell count, but high rates of mild impairment are present at all stages of HIV infection (Dawes et al., 2008; Heaton et al., 2010). HIV-associated neurocognitive impairment is of concern because it is associated with real-world impairments, including poorer medication adherence, declines in social and occupational functioning, and difficulty with instrumental activities of daily living (Doyle et al., 2013; Foley et al., 2013; Heaton et al., 2004a; Lovejoy and Suhr, 2009; Rabkin et al., 2004; Scott et al., 2011), which may be exacerbated by drug abuse (Meade et al., 2011; Morgan et al., 2014).

Drug Alcohol Depend. Author manuscript; available in PMC 2016 April 01. 
Addiction is a brain disease that disrupts neural circuitry, with reduced frontal activation in response to non-drug stimuli and altered dopaminergic transmission in limbic regions, especially the nucleus accumbens and ventral tegmental areas (Feltenstein and See, 2008; Nestler, 2005; Volkow et al., 2004). A recent meta-analysis concluded that cocaine users perform worse than controls on a range of neuropsychological tests, particularly sustained attention, memory, response inhibition, reward-based decision making, and psychomotor performance (Spronk et al., 2013). Similarly, a meta-analysis focused on methamphetamine reported poorer performance in memory, executive functioning, processing speed, motor skills, and attention (Scott et al., 2007). However, a subsequent critical review argues that modest differences have been over-interpreted, since most methamphetamine users perform within the normal range (Hart et al., 2012).

A small body of research has examined the potential additive effects of stimulant abuse and HIV infection on neurocognitive functioning. Much of this work, originating from the Western US, has focused on methamphetamine due to its relatively high prevalence in that region. Using a case-control design, one study found that HIV and methamphetamine had additive effects on rates of global neurocognitive impairment: 58\% among HIV-positive methamphetamine users, $40 \%$ among HIV-negative methamphetamine users, $38 \%$ among HIV-positive non-drug users, and 18\% among HIV-negative non-drug users (Rippeth et al., 2004). Subsequent studies also suggest that methamphetamine and HIV may have additive effects on neurocognitive impairment (Carey et al., 2006; Chang et al., 2005; Marquine et al., 2014).

While both cocaine and methamphetamine have neurotoxic effects, these stimulants appear to affect the brain differently (Simon et al., 2001; Winhusen et al., 2013), underscoring the importance of examining drug-specific effects. There has been relatively less research on the effects of cocaine on HIV-associated neurocognitive impairment. One study of HIV-infected adults found that current cocaine dependence was associated with poorer verbal memory and visuospatial construction (Meade et al., 2011). In a more recent analysis from the Women's Interagency HIV Study, frequency of crack-cocaine use was associated with poorer learning and memory in HIV-positive but not HIV-negative women (Meyer et al., 2013).

Neurobiological studies support the hypothesis that cocaine use exacerbates HIV-associated neurocognitive impairment. At the cellular and molecular levels, cocaine exposure and HIV infection produce neuronal injury via overlapping mechanisms, including increased oxidative stress, induction of inflammatory cytokines, and greater permeability of the bloodbrain-barrier (for a review, see Buch et al., 2012). Taken together, this research suggests that HIV-infected persons may be more vulnerable to cocaine-related neurocognitive impairment, but case-control designs with human subjects are needed to establish independent effects of cocaine and HIV.

While the CHARTER study concluded that substance abuse does not affect HIV-associated neurocognitive impairment, substance use risk was defined as meeting lifetime diagnostic criteria for a substance use disorder, self-report of marked lifetime substance use ( $\geq 5$ lifetime uses), or a positive urine toxicology screen (Byrd et al., 2011). Since the sample included infrequent and past users, their findings may underestimate neurocognitive impairment in active drug users. Additionally, substance use risk was collapsed across 
categories of substances (Byrd et al., 2011). To fully understand the effects of drug use on neurocognitive impairment, studies must define clear criteria for recency, frequency, and quantity of use, including careful assessment at the time of the neuropsychological testing, and consider the potential differential effects of varying classes of substances.

This is the first case-control study to investigate whether HIV infection and cocaine dependence have additive effects on neurocognitive impairment. It was hypothesized that individuals with co-occurring HIV infection and cocaine dependence would have the highest rates of global impairment. Specifically, we expected additive effects in the domains of memory and executive functioning. A comprehensive substance use assessment ensured that our cocaine groups met diagnostic criteria for lifetime dependence and were currently using the drug, while our comparison group had no history of regular cocaine abuse. Moreover, we carefully controlled for confounding conditions (e.g., head trauma, other drug abuse, serious mental illness) that could bias results.

\section{METHODS}

\subsection{Participants}

The sample included 193 adults across four groups: HIV-positive cocaine users (HIV+/COC ,$+ \mathrm{n}=48$ ), HIV-negative cocaine users (HIV-/COC+, n=53), HIV-positive non-drug users (HIV+/COC-, n=60), and HIV-negative non-drug (HIV-/COC-, n=32). For individuals with documented HIV infection, HIV status was verified by medical record review. For others, an OraQuick@ rapid HIV test was conducted; everyone who was screened tested negative. The COC+ groups had to meet the following three criteria: (1) $\_4$ days of cocaine use in the past month or a positive urine drug screen for cocaine, (2) $\geq 1$ year of regular cocaine use, and (3) lifetime cocaine dependence. The COC- groups had to meet the following five criteria: (1) no lifetime cocaine use disorder, (2) no history of regular cocaine use, (3) 0 days of cocaine use in the past year, (4) a cocaine negative drug screen, and (5) no current alcohol or marijuana dependence. In all groups, alcohol, marijuana, and nicotine use were permitted. For the COC+ groups, current alcohol and marijuana dependence were permitted if cocaine dependence was the principal diagnosis. For other drugs, individuals in all groups were excluded for lifetime abuse or dependence, history of regular use, any use in the past year, and/or a positive drug screen. Additional exclusion criteria were: English non-fluency or illiteracy; $<9^{\text {th }}$ grade education; documented severe learning disability with functional impairment; serious neurological disorders (e.g., seizure disorder, multiple sclerosis); acute opportunistic brain infections (e.g., cryptococcal meningitis, toxoplasmosis) or a history of such infections without documented return to normal cognition; severe head trauma with loss of consciousness > 30 minutes and evidence of persistent functional decline; severe mental illness, use of mood stabilizing or antipsychotic medications, or acute psychiatric distress; pregnancy; physical disabilities impeding participation (e.g., blindness); and impaired mental status. These exclusions are consistent with current guidelines for classifying contributing or confounding conditions to HIV-associated neurocognitive disorders (Antinori et al., 2007). 


\subsection{Procedures}

Participants were recruited from the Raleigh-Durham area between May, 2010 and May, 2014 via advertisements in local newspapers and websites, flyers posted and brochures distributed at community-based organizations and infectious diseases clinics, and participant referrals. Interested individuals completed a structured telephone screen to assess preliminary eligibility (e.g., HIV infection, drug use history). Eligible callers were invited for a comprehensive in-person screening.

At the screening, participants provided written informed consent. A breathalyzer was used to ensure sobriety. Participants then provided a urine sample for drug and pregnancy screening and completed clinical interviews and questionnaires. Eligible participants returned on another day to complete the neuropsychological testing, additional clinical interviews and questionnaires, and another urine drug test. Participants were paid $\$ 35$ for the screening, regardless of eligibility, and $\$ 65$ for the testing visit. All procedures were approved by the institutional review boards at Duke University Health System and University of North Carolina at Chapel Hill.

\subsection{Measures}

2.3.1. Screening measures-Module $\mathrm{E}$ of the Structured Clinical Interview for DSMIV-TR identified current and past substance dependence (First et al., 1996). The Addiction Severity Index-Lite assessed lifetime substance use and associated impairments (McLellan et al., 1992). Timeline follow-back methodology was used to assess frequency of substance use in the past 90 days (Robinson et al., 2014; Sobell and Sobell, 1996). Self-report of recent drug use was corroborated with a urine toxicology screen for cocaine, cannabis, amphetamine, methamphetamine, oxycodone, methadone, other opioids (including heroin), benzodiazepines, and barbiturates. The Mini International Neuropsychiatric Interview identified mood, anxiety, and psychotic disorders (Sheehan et al., 1998). Participants reported on their history of HIV and hepatitis $\mathrm{C}$ testing and, if applicable, HIV staging (e.g., CD4 cell counts, opportunistic infections) and treatment (RAND Corporation, 2007). The Wechsler Test of Adult Reading, which asks participants to read aloud 50 words that have atypical grapheme to phoneme translations, estimated premorbid verbal IQ (Wechsler, 2001). Finally, participants completed a computerized survey that assessed demographics and smoking history.

2.3.2. Medical record review-At screening, participants provided a release of information for us to obtain their medical record and abstract relevant data. This was critical for identifying several confounding conditions that participants did not self-disclose. For HIV clinical variables, self-report and medical record data were reconciled to yield the most complete and accurate data possible. While the medical record generally trumped selfreport, if it was incomplete, self-report was used (e.g., if the medical record did not specify the date of HIV diagnosis, but the participant was certain of the date, then self-report was used).

2.3.3. Neurocognitive functioning-Trained psychometrists administered a 60-minute battery to assess neurocognitive functioning across seven domains: 
1. Processing speed: Wechsler Adult Intelligence Scale-III (WAIS-III) Digit Symbol subtest - total number correct (Wechsler, 1997); and Trail Making Test Part A number of seconds to completion (Reitan and Wolfson, 1993).

2. Learning (immediate recall): Hopkins Verbal Learning Test - Revised (HVLT-R) - total number of words recalled on trials 1-3 (Brandt and Benedict, 2001); and Brief Visuospatial Memory Test-Revised (BVMT-R) - total score for figures correctly recalled on trials 1-3 (Benedict, 1997).

3. Memory (delayed recall): HVLT-R - number of words recalled on trial 4 (Brandt and Benedict, 2001); and BVMT-R - total score for figures correctly recalled on trial 4 (Benedict, 1997).

4. Executive functioning: Stroop Color and Word Test interference score - difference between actual and predicted score on the Color-Word trial (Golden, 1978); and Trail Making Test Part B - number of seconds to completion (Reitan and Wolfson, 1993).

5. Verbal fluency: FAS letter fluency - number of words generated; and category fluency - number of animals generated (Benton et al., 1983).

6. Attention: Paced Auditory Serial Addition Task-100 - number correct (Diehr et al., 2003); and NAB Digits Forward/Digits Backward Test - number correct (Stern and White, 2009).

7. Motor skills: Grooved Pegboard Test dominant and non-dominant hand - number of seconds to completion (Klove, 1963).

Using up-to-date published norms, raw scores were converted to demographically corrected T-scores (M=50, SD=10; Diehr et al., 2003; Heaton et al., 2004b; Norman et al., 2011; Stern and White, 2009; Wechsler, 1997). Each case was scored by two research assistants. Any discrepancies were resolved by a third research assistant re-scoring the case. 2.3.4. Other measures. At the testing visit, participants completed another computerized survey that included the 6-item depression subscale of the Brief Symptom Inventory (Derogatis, 1993). Past week depression was assessed using a 5-point scale (not at all to extremely). Participants completed another urine toxicology screen for cocaine, cannabis, methamphetamine, opioids, and benzodiazepines, and the timeline follow-back was used to assess the number of days of substance use since the screening visit.

\subsection{Data analysis plan}

We computed the Global Deficit Score (GDS), which reflects the number and severity of impaired performances on the neuropsychological test battery (Heaton et al., 1995). The GDS gives relatively less weight to performances that are within normal limits. To compute deficit scores, the T-score for each test was converted to a 0-5 deficit rating: $\mathrm{T} \geq 40=0$ (no impairment), $35-39=1,30-34=2,25-29=3,20-24=4$, and $<20=5$. The GDS was computed by adding the deficit ratings of the individual tests and dividing by the total number of tests. Domain Deficit Scores (DDS) were computed by adding the deficit ratings of the tests within each domain and dividing by the total number of tests within the domain. Impairment in a test was defined as a deficit score of $\geq 1$ (equivalent to a T-score <40). Global 
impairment on the GDS was defined as $\searrow 0.5$ and domain-specific impairment on the DDS was defined as $>0.5$; these cutoffs have been found to provide optimal sensitivity and specificity (Carey et al., 2004).

Descriptive statistics were used to characterize the sample. We then examined differences between groups on DDS and GDS using 2 (HIV+/HIV-) $\times 2$ (COC+/COC-) betweensubjects general linear model analyses. To test the additive risk of HIV and cocaine on DDS and GDS scores, we used the nonparametric Jonckheere-Terpstra test for ordered alternatives (Jonckheere, 1954; Terpstra, 1952). This between group trend test assesses whether the distribution of median deficit scores differs based on number of risk factors (COC-/HIV- $=0, \mathrm{COC}+/ \mathrm{HIV}$ - or COC-/HIV $+=1, \mathrm{COC}+/ \mathrm{HIV}+=2$ ). We also ran parallel analyses using the three patient groups compared to the control group (i.e., COC-/HIV-). Finally, we conducted multivariate logistic models to predict global and domain-specific impairment as a function of cocaine dependence and HIV infection.

\section{RESULTS}

\subsection{Participant characteristics}

The sample included 128 men and 65 women, primarily non-Hispanic (97\%) and AfricanAmerican (85\%), who ranged in age from 19 to 70 years $(M=46.09, S D=9.86)$. Table 1 compares the four groups on demographic, substance abuse, HIV, and other characteristics. The majority (85\%) had a high school education, but cocaine users had significantly fewer years of education compared to non-drug users. The groups also differed on premorbid verbal IQ and current depressive symptoms.

Among the COC+ groups, participants had been using cocaine regularly for an average of 17.88 years $(\mathrm{SD}=7.43$, range $2-34)$. The predominant route of cocaine administration was smoking (88\%); no one reported current injection. The COC+/HIV- group used cocaine on more days in the past 90 days, but both groups used it frequently $(\mathrm{M}=32.43, \mathrm{SD}=23.85)$. The $\mathrm{COC}+$ groups were significantly more likely than the COC- groups to report current use of alcohol to intoxication, marijuana, and nicotine. Among participants who reported alcohol to intoxication, the $\mathrm{COC}+$ groups also reported more days of use.

The HIV+ participants had been diagnosed with HIV for an average of 12.89 years ( $\mathrm{SD}=7.34$, range 5 months to 32 years). The $\mathrm{COC}+/ \mathrm{HIV}+$ and $\mathrm{COC}-/ \mathrm{HIV}+$ groups were comparable on current and nadir CD4 cell counts, AIDS diagnosis, and suppressed viral load $(<50$ copies $/ \mathrm{mL})$.

\subsection{Domain and global deficit scores}

Table 2 lists the raw scores and demographically corrected T-scores for each task by group. Table 3 summarizes the DDS and GDS. A main effect of cocaine was observed in processing speed and executive functioning, with the $\mathrm{COC}+$ groups having greater impairment compared to the COC- groups in both cases. A main effect of HIV was observed in attention, with the HIV+ groups having greater impairment than the HIV-groups. A significant $\mathrm{HIV}^{*} \mathrm{COC}$ interaction was found in executive functioning, such that the three patient groups had greater impairment than the control group. A similar significant 
interaction was found for verbal fluency, though the magnitude of impairment scores was relatively low across all groups. The Jonckheere-Terpstra test was significant only for processing speed $\left(\mathrm{J}^{*}\right.$ statistic $\left.=3.36, \mathrm{p}=.001\right)$, indicating additive risk in the presence of both HIV and cocaine.

\subsection{Rates of neurocognitive impairment}

Figure 1 illustrates the rates of impairment globally and by domain, and summarizes the results of multivariate logistic regression models predicting impairment as a function of cocaine dependence and HIV infection. Based on the GDS, the rate of global impairment in the sample was 33\%, with no significant main effects of cocaine dependence or HIV infection. For processing speed, there was a significant main effect of cocaine, with the COC + groups being 3.34 times more likely than the COC-groups to have impairment. All models were repeated with the addition of a COC*HIV interaction term, and the only significant interaction effect was found in executive functioning [AOR=0.07 (0.01-0.70), $\mathrm{p}=.023]$. The patterns of results did not change when controlling for premorbid verbal IQ, depressive symptoms at testing, any alcohol to intoxication, any marijuana use, any nicotine use, and any history of hepatitis $\mathrm{C}$ diagnosis; therefore, the original results (without the control variables included) are presented.

Among COC+ participants, there was no association between global impairment based on the GDS and years of regular cocaine use [AOR=0.98 (0.93-1.04)], heavy cocaine use in the past 90 days $[\mathrm{AOR}=0.69(0.30-1.57)]$, a positive urine drug screen at testing $[\mathrm{AOR}=0.79$ $(0.26-2.36)]$, alcohol use to intoxication in the past 90 days [AOR=0.82 (0.35-1.92)], and marijuana use in the past 90 days [AOR=0.71 (0.31-1.62)]. Among HIV+ participants, there was no association between global impairment and years since HIV diagnosis [AOR=1.01 (0.95-1.06)], suppressed viral load [AOR=1.49 (0.67-3.33)], nadir CD4 cell count [AOR=1.00 (1.00-1.00)], current CD4 cell count [AOR=1.00 (1.00-1.00)], AIDS diagnosis [AOR=0.93 (0.42-2.07)], or being on an Efavirenz-based ART regimen [AOR=1.39 $(0.61-3.18)]$.

\section{DISCUSSION}

Despite the relatively high prevalence of cocaine use among HIV-infected persons (e.g., Mimiaga et al., 2013), this is the first case-control study designed to isolate the independent effects of cocaine and HIV on neurocognitive impairment. The rate of global impairment, based on the GDS, was 33\%, and neither cocaine dependence nor HIV infection significantly increased the risk of global impairment. However, both conditions had independent effects in specific, different cognitive domains. Individuals with cocaine dependence and/or HIV infection had significantly greater deficits in processing speed, executive functioning, and attention, with additive effects in the domain of processing speed.

While cocaine dependence did not appear to increase vulnerability to global HIV-associated neurocognitive impairment, we did identify main effects in executive functioning and processing speed. This finding is consistent with several prior studies that also reported greater impairments in cocaine users compared to healthy controls in executive functioning, specifically response inhibition (Fernandez-Serrano et al., 2012; Fillmore and Rush, 2002; 
Kjome et al., 2010) and reward-based decision making (Camchong et al., 2011; Kjome et al., 2010; Lane et al., 2010). Impairments in executive functioning are theorized to play a role in the maintenance of drug addiction (Bechara, 2005; Schoenbaum et al., 2006) and have been found to predict poorer outcomes in response to drug treatment (Stevens et al., 2014). In contrast, most studies report no effects of cocaine on processing speed (Spronk et al., 2013), suggesting that deficits in this domain may become more prominent in the context of HIV infection. Given prior research indicating that cognitive deficits are less pronounced in cocaine users with a positive drug screen (Woicik et al., 2009), current cocaine use in our sample may have masked additional underlying cognitive impairments.

Compared to the CHARTER study, in which approximately half of HIV-infected Americans demonstrated neurocognitive impairment, with prominent deficits in learning, memory, attention, and executive functioning (Heaton et al., 2010), we found that HIV had an independent effect only in the domain of attention. Our results are consistent with two recent studies that reported no difference in neurocognitive impairment between HIV-positive and HIV-negative participants using the GDS algorithm among: British men who have sex with men (32\% and 27\%, respectively; McDonnell et al., 2014) and US military beneficiaries (19\% vs. 30\% respectively; Crum-Cianflone et al., 2013). In a Danish Nationwide Cohort Study, the rate of severe neurocognitive disorders in HIV-infected persons dropped by half after 2004 when the use of combination ART became widespread, with rates almost comparable to healthy controls (Lescure et al., 2011). Crum-Cianflone et al (2013) suggested that early recognition and management of HIV infection in their sample, in which only $15 \%$ had low $\left(<200\right.$ cells $\left./ \mathrm{mm}^{3}\right)$ nadir CD4 counts, may have protected against the development of neurocognitive impairment. In our sample, participants had been living with HIV for a mean of 12 years, some for over two decades, and over half had a history of low nadir CD4 counts; however, all were currently engaged in HIV care, and only one person was not yet receiving combination ART. In contrast, only $71 \%$ of CHARTER participants were on ART at time of testing (Heaton et al., 2010). Taken together, these studies suggest that continued improvements in ART regimens, coupled with earlier initiation of these medications, may have a positive impact on neurocognitive functioning. However, it is important to note that the HIV-negative controls in our sample demonstrated relatively high levels of impairment across several domains (e.g., 38\% impairment in learning), which may have masked more subtle effects of HIV within these domains.

Additional design considerations may have contributed to the relatively low HIV-associated neurocognitive impairment in our sample. First, we had strict eligibility criteria to eliminate the potential confounding effects of comorbid conditions. In contrast, the CHARTER study had no formal exclusion criteria. When participants were classified based on commonly encountered comorbidities, the rate of neurocognitive impairment was $83 \%$ in participants with confounding conditions compared to 59\% in those with contributing and $40 \%$ in those with incidental conditions (Heaton et al., 2010). Second, we applied the most up-to-date norms to correct for demographic factors, including age, education, gender, and race, which are known to affect neuropsychological test performance (Diehr et al., 2003; Heaton et al., 2004b; Manly et al., 2005; Norman et al., 2000). For example, neurocognitive impairment was significantly overestimated in African-Americans when using previously published normative standards (Norman et al., 2011). Given that the vast majority of our participants 
were African-American, many with low educational attainment, the availability of these new norms was important for accurately estimating neurocognitive impairment.

Despite the strong case-control design and comprehensive assessment of substance use to isolate the effects of HIV and cocaine, this study had several notable limitations. First, due to the cross-sectional design, it is not possible to determine whether differences between the study groups preceded the onset of cocaine dependence and/or HIV infection. Second, because our sample included HIV-negative persons, we used the GDS to estimate prevalence of neurocognitive impairment, rather than the Frascati criteria, which are specific for diagnosing HIV-associated disorders. Third, while comparable in demographic and socio-economic characteristics, our control group performed unexpectedly poorly on tasks involving learning and motor skills, and demonstrated higher verbal IQ and lower depression relative to the three patient groups. However, results did not change when we controlled for these and other potential confounds. Finally, as expected given high rates of poly-substance use among cocaine users (Fischer et al., 2010; Harrell et al., 2012; Roy et al., 2013), the cocaine groups were more likely to use alcohol and marijuana, but use of these substances was not related to global impairment.

The findings of this case-control study highlight the complexity of neurocognitive impairment in the context of HIV infection and cocaine use. While cocaine dependence did not increase vulnerability to global HIV-associated neurocognitive impairment, it was associated with deficits in several domains. Specifically, individuals with cocaine dependence and/or HIV infection demonstrated greater impairments in executive functioning, processing speed, and attention, and additive effects of cocaine and HIV were observed in processing speed. As demonstrated in prior studies of HIV-associated neurocognitive impairment, these domain-specific deficits have real-world implications, including impairments in occupational functioning, medication management, driving, and multi-tasking (Doyle et al., 2013; Foley et al., 2013; Heaton et al., 2004a; Lovejoy and Suhr, 2009; Rabkin et al., 2004; Scott et al., 2011). These impairments may help to explain the generally poorer behavioral and functional outcomes observed in HIV-infected stimulant users. Longitudinal studies are necessary to examine within-subject changes in neurocognitive functioning in relation to drug addiction and HIV disease progression. As we continue to learn more about how drug abuse and HIV infection affect the brain in the era of improved ART regimens, it is important for future research to identify effective interventions to improve neurocognitive outcomes.

\section{Acknowledgements}

We thank all the men and women who participated in this study.

Role of Funding Source

This study was funded by grants K23-DA028660, T32-AI007392, and F31-DA035131 from the United States National Institutes of Health. We are grateful to the UNC Center for AIDS Research (P30-AI50410) for its assistance with patient recruitment. The NIH had no further role in study design, data collection, analysis and interpretation of data, writing the report, or in the decision to submit the paper for publication. 


\section{References}

Antinori A, Arendt G, Becker JT, Brew BJ, Byrd DA, Cherner M, Clifford DB, Cinque P, Epstein LG, Goodkin K, Gisslen M, Grant I, Heaton RK, Joseph J, Marder K, Marra CM, McArthur JC, Nunn M, Price RW, Pulliam L, Robertson KR, Sacktor N, Valcour V, Wojna VE. Updated research nosology for HIV-associated neurocognitive disorders. Neurology. 2007; 69:1789-1799. doi: 10.1212/01.WNL.0000287431.88658.8b. [PubMed: 17914061]

Bechara A. Decision making, impulse control and loss of willpower to resist drugs: a neurocognitive perspective. Nat. Neurosci. 2005; 8:1458-1463. doi: 10.1038/nn1584. [PubMed: 16251988]

Benedict, RH. Brief Visuospatial Memory Test-Revised Professional Manual. Psychological Assessment Resources, Inc.; Odessa, FL.: 1997.

Benton, A.; Hamsher, K.; Sivan, A. Multilingual Aphasia Examination. 3rd edition. AJA Associates; Iowa City, IA.: 1983.

Bing EG, Burnam MA, Longshore D, Fleishman JA, Sherbourne CD, London AS, Turner BJ, Eggan F, Beckman R, Vitiello B, Morton SC, Orlando M, Bozzette SA, Ortiz-Barron L, Shapiro M. Psychiatric disorders and drug use among human immunodeficiency virus-infected adults in the United States. Arch. Gen. Psychiatry. 2001; 58:721-728. doi: 10.1001/archpsyc.58.8.721. [PubMed: 11483137]

Brandt, J.; Benedict, RHB. Hopkins Verbal Learning Test -- Revised Professional Manual. Psychological Assessment Resources, Inc; Lutz, FL.: 2001.

Brew BJ, Gonzalez-Scarano F. HIV-associated dementia: an inconvenient truth. Neurology. 2007; 68:324-325. doi: 10.1212/01.wnl.0000252803.24176.76. [PubMed: 17261677]

Buch S, Yao H, Guo M, Mori T, Seth P, Wang J, Su TP. Cocaine and HIV-1 interplay in CNS: cellular and molecular mechanisms. Curr. HIV Res. 2012; 10:425-428. doi: CHIVR-EPUB-20120511-4 [pii]. [PubMed: 22591366]

Byrd DA, Fellows RP, Morgello S, Franklin D, Heaton RK, Deutsch R, Atkinson JH, Clifford DB, Collier AC, Marra CM, Gelman B, McCutchan JA, Duarte NA, Simpson DM, McArthur J, Grant I, Charter Group. Neurocognitive impact of substance use in HIV infection. J. Acquir. Immune. Defic. Syndr. 2011; 58:154-162. doi: 10.1097/QAI.0b013e318229ba41. [PubMed: 21725250]

Camchong J, MacDonald AW III, Nelson B, Bell C, Mueller BA, Specker S, Lim KO. Frontal hyperconnectivity related to discounting and reversal learning in cocaine subjects. Biol. Psychiatry. 2011; 69:1117-1123. doi: 10.1016/j.biopsych.2011.01.008. [PubMed: 21371689]

Carey CL, Woods SP, Gonzalez R, Conover E, Marcotte TD, Grant I, Heaton RK. Predictive validity of global deficit scores in detecting neuropsychological impairment in HIV infection. J. Clin. Exp. Neuropsychol. 2004; 26:307-319. doi: 10.1080/13803390490510031. [PubMed: 15512922]

Carey CL, Woods SP, Rippeth JD, Gonzalez R, Heaton RK, Grant I. Additive deleterious effects of methamphetamine dependence and immunosuppression on neuropsychological functioning in HIV infection. AIDS Behav. 2006; 10:185-190. doi: 10.1007/s10461-005-9056-4. [PubMed: 16477511]

Chang L, Lee PL, Speck O, Grob CS. Additive effects of HIV and chronic methamphetamine use on brain metabolite abnormalities Am. J. Psychiatry. 2005; 162:361-369.

Crum-Cianflone NF, Moore DJ, Letendre S, Poehlman Roediger M, Eberly L, Weintrob A, Ganesan A, Johnson E, Del Rosario R, Agan BK, Hale BR. Low prevalence of neurocognitive impairment in early diagnosed and managed HIV-infected persons. Neurology. 2013; 80:371-379. doi: 10.1212/WNL.0b013e31827f0776. [PubMed: 23303852]

Dawes S, Suarez P, Casey CY, Cherner M, Marcotte TD, Letendre S, Grant I, Heaton RK. Variable patterns of neuropsychological performance in HIV-1 infection. J. Clin. Exp. Neuropsychol. 2008; 30:613-626. doi: 10.1080/13803390701565225. [PubMed: 18608689]

Derogatis, LR. Brief Symptom Inventory: Administration, Scoring, and Procedures Manual. 3rd ed.. National Computer Systems, Inc.; Minneapolis, MN.: 1993.

Diehr MC, Cherner M, Wolfson TJ, Miller SW, Grant I, Heaton RK. The 50 and 100-item short forms of the Paced Auditory Serial Addition Task (PASAT): demographically corrected norms and comparisons with the full PASAT in normal and clinical samples. J. Clin. Exp. Neuropsychol. 2003; 25:571-585. doi: 10.1076/jcen.25.4.571.13876. [PubMed: 12911108] 
Doyle KL, Morgan EE, Morris S, Smith DM, Little S, Iudicello JE, Blackstone K, Moore DJ, Grant I, Letendre SL, Woods SP. Real-world impact of neurocognitive deficits in acute and early HIV infection. J. Neurovirol. 2013; 19:565-573. doi: 10.1007/s13365-013-0218-2. [PubMed: 24277439]

Feltenstein MW, See RE. The neurocircuitry of addiction: an overview. Br. J. Pharmacol. 2008; 154:261-274. doi: 10.1038/bjp.2008.51. [PubMed: 18311189]

Fernandez-Serrano MJ, Perales JC, Moreno-Lopez L, Perez-Garcia M, Verdejo-Garcia A. Neuropsychological profiling of impulsivity and compulsivity in cocaine dependent individuals. Psychopharmacology. 2012; 219:673-683. doi: 10.1007/s00213-011-2485-z. [PubMed: 21922168]

Fillmore MT, Rush CR. Impaired inhibitory control of behavior in chronic cocaine users. Drug Alcohol Depend. 2002; 66:265-273. doi: 10.1016/S0376-8716(01)00206-X. [PubMed: 12062461]

First, MB.; Spitzer, RL.; Gibbon, M.; Williams, JBW. New York State Psychiatric Institute; New York: 1996. Biometrics Research. Structured Clinical Interview for DSM-IV Axis I Disorders, Research Version, Patient/Non-patient Edition..

Fischer, Benedikt, Rudzinski, Katherine, Ivsins, Andrew, Gallupe, Owen, Patra, Jayadeep, Krajden, Mel. Social, health and drug use characteristics of primary crack users in three mid-sized communities in British Columbia, Canada. Drugs: Educ. Prev. Policy. 2010; 17:333-353. doi: 10.3109/09687630903357700.

Foley JM, Gooding AL, Thames AD, Ettenhofer ML, Kim MS, Castellon SA, Marcotte TD, Sadek JR, Heaton RK, van Gorp WG, Hinkin CH. Visuospatial and Attentional Abilities Predict Driving Simulator Performance Among Older HIV-infected Adults. Am. J. Alzheimer's Dis. Other Dementias. 2013; 28:185-194. doi: 10.1177/1533317512473192.

Escriva, Garin; Noe; Muñoz, Velasco; Cesar; De Pourcq, Thomas; Jan; Garcia, Lopez; Belen; Haro Abad, Maria; Josep; Mangues Bafalluy, Antonia; Maria; Garcia, Trilla; Antoni. Recreational drugs and HIV in Europe: current use of recreational drugs and principal HIV guidelines related recommendations. J. Int. AIDS Soc. 2014; 17:19831. doi: 10.7448/IAS.17.4.19831. [PubMed: 25397575]

Golden, CJ. Stroop Color and Word Test. Stoelting; Chicago, IL.: 1978.

Harrell PT, Mancha BE, Petras H, Trenz RC, Latimer WW. Latent classes of heroin and cocaine users predict unique HIV/HCV risk factors. Drug Alcohol Depend. 2012; 122:220-227. doi: 10.1016/ j.drugalcdep.2011.10.001. [PubMed: 22030276]

Hart, Carl L, Marvin, Caroline B, Silver, Rae, Smith, Edward E. Is cognitive functioning impaired in methamphetamine users? A critical review. Neuropsychopharmacology. 2012; 37:586-608. doi: 10.1038/npp.2011.276. [PubMed: 22089317]

Heaton RK, Clifford DB, Franklin DR Jr. Woods SP, Ake C, Vaida F, Ellis RJ, Letendre SL, Marcotte TD, Atkinson JH, Rivera-Mindt M, Vigil OR, Taylor MJ, Collier AC, Marra CM, Gelman BB, McArthur JC, Morgello S, Simpson DM, McCutchan JA, Abramson I, Gamst A, FennemaNotestine C, Jernigan TL, Wong J, Grant I. HIV-associated neurocognitive disorders persist in the era of potent antiretroviral therapy: CHARTER Study. Neurology. 2010; 75:2087-2096. doi: 10.1212/WNL.0b013e318200d727. [PubMed: 21135382]

Heaton RK, Franklin D, Ellis R, McCutchan J, Letendre S, LeBlanc S, Corkran S, Duarte N, Clifford D, Woods S, Collier A, Marra C, Morgello S, Mindt M, Taylor M, Marcotte T, Atkinson J, Wolfson T, Gelman B, McArthur J, Simpson D, Abramson I, Gamst A, Fennema-Notestine C, Jernigan T, Wong J, Grant I. HIV-associated neurocognitive disorders before and during the era of combination antiretroviral therapy: differences in rates, nature, and predictors. J. Neurovirol. 2011; 17:3-16. doi: 10.1007/s13365-010-0006-1. [PubMed: 21174240]

Heaton RK, Grant I, Butters N, White DA, Kirson D, Atkinson JH, McCutchan JA, Taylor MJ, Kelly MD, Ellis RJ, et al. The HNRC 500--neuropsychology of HIV infection at different disease stages. HIV Neurobehavioral Research Center. J. Int. Neuropsychol. Soc. 1995; 1:231-251. doi: 10.1017/ S1355617700000230.

Heaton RK, Marcotte TD, Mindt MR, Sadek J, Moore DJ, Bentley H, McCutchan JA, Reicks C, Grant I. The impact of HIV-associated neuropsychological impairment on everyday functioning. J. Int. Neuropsychol. Soc. 2004a; 10:317-331. doi: 10.1017/S1355617704102130. [PubMed: 15147590] 
Heaton, RK.; Miller, SW.; Taylor, MJ.; Grant, I. Revised Comprehensive Norms for an Expanded Halstead-Reitan Battery: Demographically Adjusted Neuropsychological Norms for African American and Caucasian Adults. Psychological Assessment Resources, Inc; Lutz, FL.: 2004b.

Jonckheere AR. A distribution-free k-sample test against ordered alternatives. Biometrika. 1954; 41:133-145.

Kjome KL, Lane SD, Schmitz JM, Green C, Ma L, Prasla I, Swann AC, Moeller F. Relationship between impulsivity and decision making in cocaine dependence. Psychiatry Res. 2010; 178:299304. doi: 10.1016/j.psychres.2009.11.024. [PubMed: 20478631]

Klove, H. Grooved Pegboard. Lafayette Instruments; Lafayette, IN.: 1963.

Lane SD, Steinberg JL, Ma L, Hasan KM, Kramer LA, Zuniga EA, Narayana PA, Moeller FG. Diffusion tensor imaging and decision making in cocaine dependence. PLoS One. 2010; 5:e11591. doi: 10.1371/journal.pone.0011591. [PubMed: 20661285]

Lescure FX, Omland LH, Engsig FN, Roed C, Gerstoft J, Pialoux G, Kronborg G, Larsen CS, Obel N. Incidence and impact on mortality of severe neurocognitive disorders in persons with and without HIV infection: a Danish nationwide cohort study. Clin. Infect. Dis. 2011; 52:235-243. doi: 10.1093/cid/ciq041. [PubMed: 21288850]

Lovejoy TI, Suhr JA. The relationship between neuropsychological functioning and HAART adherence in HIV-positive adults: a systematic review. J. Behav. Med. 2009; 32:389-405. doi: 10.1007/s10865-009-9212-9. [PubMed: 19291386]

Manly JJ, Schupf N, Tang MX, Stern Y. Cognitive decline and literacy among ethnically diverse elders. J. Geriatr. Psychiatry Neurol. 2005; 18:213-217. doi: 10.1177/0891988705281868. [PubMed: 16306242]

Marquine MJ, Iudicello JE, Morgan EE, Brown GG, Letendre SL, Ellis Ronald J. Deutsch R, Woods SP, Grant I, Heaton RK. "Frontal systems" behaviors in comorbid human immunodeficiency virus infection and methamphetamine dependency. Psychiatry Res. 2014; 215:208-216. doi: 10.1016/ j.psychres.2013.11.004. [PubMed: 24290100]

McDonnell J, Haddow L, Daskalopoulou M, Lampe F, Speakman A, Gilson R, Phillips A, Sherr L, Wayal S, Harrison J, Antinori A, Maruff P, Schembri A, Johnson M, Collins S, Rodger A. Minimal cognitive impairment in UK HIV positive men who have sex with men: effect of case definitions, and comparison with the general population and HIV negative men. J. Acquir. Immune. Defic. Syndr. doi. 2014 10.1097/qai.0000000000000273.

McLellan AT, Kushner H, Metzger D, Peters R, Smith I, Grissom G, Pettinati H, Argeriou M. The fifth edition of the Addiction Severity Index. J. Subst. Abuse Treat. 1992; 9:199-213. [PubMed: 1334156]

Meade CS, Conn NA, Skalski LM, Safren SA. Neurocognitive impairment and medication adherence in HIV patients with and without cocaine dependence. J. Behav. Med. 2011; 34:128-138. doi: 10.1007/s10865-010-9293-5. [PubMed: 20857187]

Meyer JV, Rubin LH, Martin E, Weber KM, Cohen MH, Golub ET, Valcour V, Young MA, Crystal H, Anastos K, Aouizerat BE, Milam J, Maki PM. HIV and recent illicit drug use interact to affect verbal memory in women. J. Acquir. Immune. Defic. Syndr. 2013; 63:67-76. doi: 10.1097/QAI. 0b013e318289565c. [PubMed: 23392462]

Mimiaga MJ, Reisner SL, Grasso C, Crane HM, Safren SA, Kitahata MM, Schumacher JE, Mathews WC, Mayer KH. Substance use among HIV-infected patients engaged in primary care in the United States: findings from the Centers for AIDS Research Network of Integrated Clinical Systems cohort. Am. J. Public Health. 2013; 103:1457-1467. doi: 10.2105/ajph.2012.301162. [PubMed: 23763417]

Morgan EE, Doyle KL, Minassian A, Henry BL, Perry W, Marcotte TD, Paul Woods S, Grant I. Elevated intraindividual variability in methamphetamine dependence is associated with poorer everyday functioning. Psychiatry Res. 2014; 220:527-534. doi: 10.1016/j.psychres.2014.07.008. [PubMed: 25081313]

Nestler EJ. Is there a common molecular pathway for addiction? Nat. Neurosci. 2005; 8:1445-1449. doi: 10.1038/nn1578. [PubMed: 16251986] 
Norman MA, Evans JD, Miller WS, Heaton RK. Demographically corrected norms for the California Verbal Learning Test. J. Clin. Exp. Neuropsychol. 2000; 22:80-94. doi: 10.1076/1380-3395(200002)22:1;1-8;FT080. [PubMed: 10649547]

Norman MA, Moore DJ, Taylor M, Franklin D Jr. Cysique L, Ake C, Lazarretto D, Vaida F, Heaton RK, Hnrc Group. Demographically corrected norms for African Americans and Caucasians on the Hopkins Verbal Learning Test-Revised, Brief Visuospatial Memory Test-Revised, Stroop Color and Word Test, and Wisconsin Card Sorting Test 64-Card Version. J. Clin. Exp. Neuropsychol. 2011; 33:793-804. doi: 10.1080/13803395.2011.559157. [PubMed: 21547817]

Pence BW, Thielman NM, Whetten K, Ostermann J, Kumar V, Mugavero MJ. Coping strategies and patterns of alcohol and drug use among HIV-infected patients in the United States Southeast. AIDS Patient Care STDS. 2008; 22:869-877. doi: 10.1089/apc.2008.0022. [PubMed: 19025481]

Rabkin JG, McElhiney M, Ferrando SJ, Van Gorp W, Lin SH. Predictors of employment of men with HIV/AIDS: a longitudinal study. Psychosom. Med. 2004; 66:72-78. doi: 10.1097/01.PSY. 0000108083.43147.6D. [PubMed: 14747640]

RAND Corporation. HIV Cost And Services Utilization Study (HCSUS) Baseline Questionnaire. RAND Corporation; Santa Monica, CA.: 2007.

Reif SS, Whetten K, Wilson ER, McAllaster C, Pence BW, Legrand S, Gong W. HIV/AIDS in the Southern USA: A disproportionate epidemic. AIDS Care. 2013; 26:351-359. doi: 10.1080/09540121.2013.824535. [PubMed: 23944833]

Reitan, RM.; Wolfson, D. The Halstead-Reitan Neuropsychological Test Battery: Theory And Clinical Interpretation. 2nd ed.. Neuropsycholgy Press Tucson; AZ.: 1993.

Rippeth JD, Heaton RK, Carey CL, Marcotte TD, Moore DJ, Gonzalez R, Wolfson T, Grant I. Methamphetamine dependence increases risk of neuropsychological impairment in HIV infected persons. J. Int. Neuropsychol. Soc. 2004; 10:1-14. doi: 10.1017/S1355617704101021. [PubMed: 14751002]

Robinson SM, Sobell LC, Sobell MB, Leo GI. Reliability of the Timeline Followback for cocaine, cannabis, and cigarette use. Psychol. Addict. Behav. 2014; 28:154-162. doi: 10.1037/a0030992. [PubMed: 23276315]

Roy É, Richer I, Arruda N, Vandermeerschen J, Bruneau J. Patterns of cocaine and opioid co-use and polyroutes of administration among street-based cocaine users in Montréal, Canada. Int. J. Drug Policy. 2013; 24:142-149. doi: 10.1016/j.drugpo.2012.10.004. [PubMed: 23182550]

Sacktor N. The epidemiology of human immunodeficiency virus-associated neurological disease in the era of highly active antiretroviral therapy. J. Neurovirol. 2002; 8:115-121. doi: 10.1080/13550280290101094. [PubMed: 12491162]

Schoenbaum G, Roesch MR, Stalnaker TA. Orbitofrontal cortex, decision-making and drug addiction. Trends Neurosci. 2006; 29:116-124. doi: 10.1016/j.tins.2005.12.006. [PubMed: 16406092]

Scott JC, Woods SP, Matt GE, Meyer RA, Heaton RK, Atkinson JH, Grant I. Neurocognitive effects of methamphetamine: a critical review and meta-analysis. Neuropsychol. Rev. 2007; 17:275-297. doi: 10.1007/s11065-007-9031-0. [PubMed: 17694436]

Scott JC, Woods SP, Vigil O, Heaton RK, Schweinsburg BC, Ellis RJ, Grant I, Marcotte TD. A neuropsychological investigation of multitasking in HIV infection: implications for everyday functioning. Neuropsychology. 2011; 25:511-519. doi: 10.1037/a0022491. [PubMed: 21401259]

Sheehan DV, Lecrubier Y, Sheehan KH, Amorim P, Janavs J, Weiller E, Hergueta T, Baker R, Dunbar GC. The Mini International Neuropsychiatric Interview (M.I.N.I.): the development and validation of a structured diagnostic psychiatric interview for DSM-IV and ICD-10. J. Clin. Psychiatr. 1998; 59:22-33.

Siconolfi DE, Halkitis PN, Barton SC, Kingdon MJ, Perez-Figueroa RE, Arias-Martinez V, Karpiak S, Brennan-Ing M. Psychosocial and demographic correlates of drug use in a sample of HIV-positive adults ages 50 and older. Prev. Sci. 2013; 14:618-627. doi: 10.1007/s11121-012-0338-6. [PubMed: 23408281]

Simon SL, Domier CP, Sim T, Richardson K, Rawson RA, Ling W. Cognitive performance of current methamphetamine and cocaine abusers. J. Addict. Dis. 2001; 21:61-74. doi: 10.1300/ J069v21n01_06. [PubMed: 11831501] 
Sobell, LC.; Sobell, MB. Timeline Follow-back User's Guide: A Calendar Method for Assessing Alcohol and Drug Use. Addiction Research Foundation; Toronto: 1996.

Spronk DB, van Wel JHP, Ramaekers JG, Verkes RJ. Characterizing the cognitive effects of cocaine: a comprehensive review. Neurosci. Biobehav. Rev. 2013; 37:1838-1859. doi: 10.1016/ j.neubiorev.2013.07.003. [PubMed: 23876288]

Stern, RA.; White, T. NAB Digits Forward/Digits Backward Test: Professional Manual. Psychological Assessment Resources, Inc. (PAR); Lutz, FL.: 2009.

Stevens L, Verdejo-García A, Goudriaan AE, Roeyers H, Dom G, Vanderplasschen W. Impulsivity as a vulnerability factor for poor addiction treatment outcomes: a review of neurocognitive findings among individuals with substance use disorders. J. Subst. Abuse Treat. 2014; 47:58-72. doi: 10.1016/j.jsat.2014.01.008. [PubMed: 24629886]

Terpstra TJ. The asymptotic normality and consistency of Kendall's test against trend, when ties are present in one ranking. Indagationes Mathematicae. 1952; 14:327-333.

US Department of Justice. National Drug Threat Assessment. Johnstown, PA.: 2011.

Valcour V, Sithinamsuwan P, Letendre S, Ances B. Pathogenesis of HIV in the central nervous system. Curr. HIV AIDS Rep. 2011; 8:54-61. doi: 10.1007/s11904-010-0070-4.

Volkow ND, Fowler JS, Wang GJ, Swanson JM. Dopamine in drug abuse and addiction: results from imaging studies and treatment implications. Mol. Psychiatry. 2004; 9:557-569. doi: 10.1038/ sj.mp.4001507. [PubMed: 15098002]

Wechsler, D. Wechsler Adult Intelligence Scale--Third Edition: Administration and Scoring Manual. Harcourt Brace; San Antonio, TX.: 1997.

Wechsler, D. Wechsler Test of Adult Reading (WTAR) Manual. Harcourt Assessment; San Antonio, TX.: 2001.

Winhusen T, Lewis D, Adinoff B, Brigham G, Kropp F, Donovan DM, Seamans CL, Hodgkins CC, DiCenzo JC, Botero CL, Jones DR, Somoza E. Impulsivity is associated with treatment noncompletion in cocaine- and methamphetamine-dependent patients but differs in nature as a function of stimulant-dependence diagnosis. J. Subst. Abuse Treat. 2013; 44:541-547. doi: 10.1016/j.jsat.2012.12.005. [PubMed: 23305820]

Woicik PA, Moeller SJ, Alia-Klein N, Maloney T, Lukasik TM, Yeliosof O, Wang GJ, Volkow ND, Goldstein RZ. The neuropsychology of cocaine addiction: recent cocaine use masks impairment. Neuropsychopharmacology. 2009; 34:1112-1122. doi: 10.1038/npp.2008.60. [PubMed: 18496524] 


\section{RESEARCH HIGHLIGHTS}

- We examined the effects of HIV infection and cocaine on neurocognitive impairment.

- HIV and cocaine had independent effects on impairment, but in different domains.

- Cocaine use did not increase risk of overall HIV-associated impairment.

- Cocaine was associated with deficits in processing speed and executive functions.

- These deficits likely contribute to poorer behavioral and functional outcomes. 


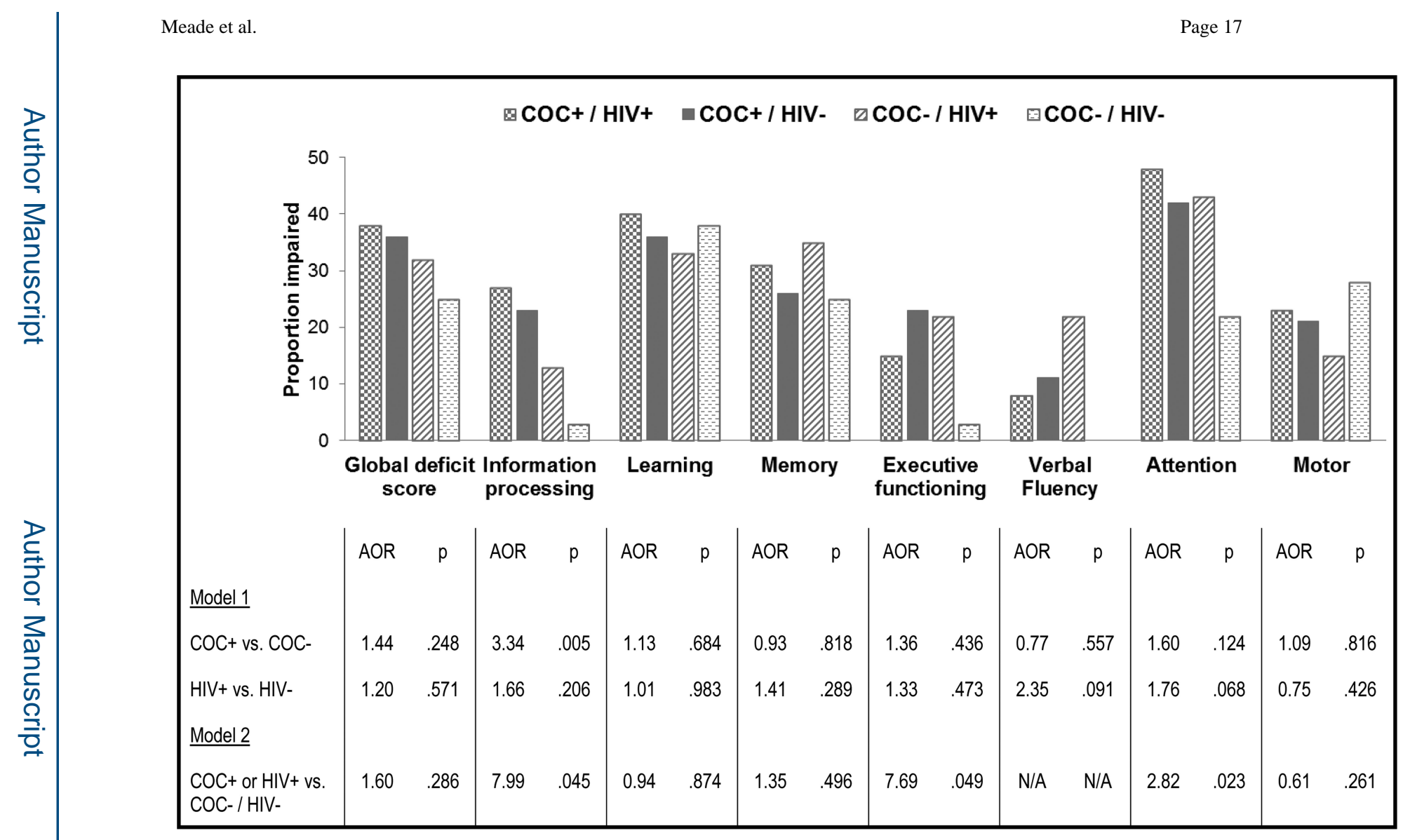

Figure 1.

Rates of impairment globally and by cognitive domain as a function of cocaine and HIV status ( $\mathrm{N}=193)$. Multivariate logistic regression models provide the adjusted odds of impairment as a function of cocaine dependence and HIV infection. AOR = adjusted odds ratio. In model 1, cocaine dependence and HIV infection were entered in a single block. In model 2, participants with HIV and/or cocaine were compared with the control group. The pattern of results did not change when adjusting for premorbid verbal IQ, depression symptoms at testing, any alcohol to intoxication, any marijuana use, any nicotine use, and any history of hepatitis $\mathrm{C}$ diagnosis. The analyses were not run for verbal fluency due to there being no cases of impairment in the control group. 

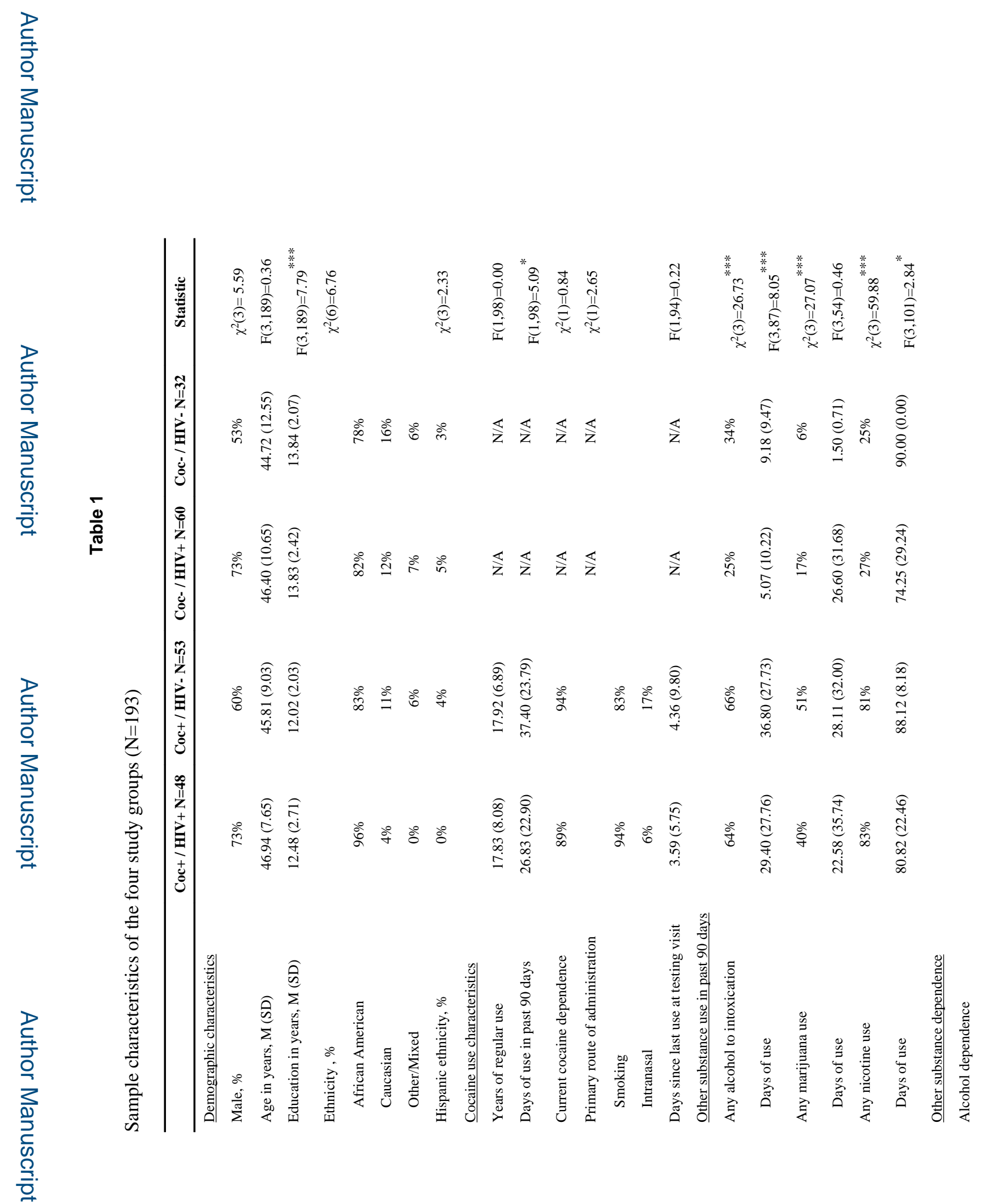

Drug Alcohol Depend. Author manuscript; available in PMC 2016 April 01. 


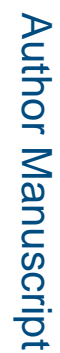

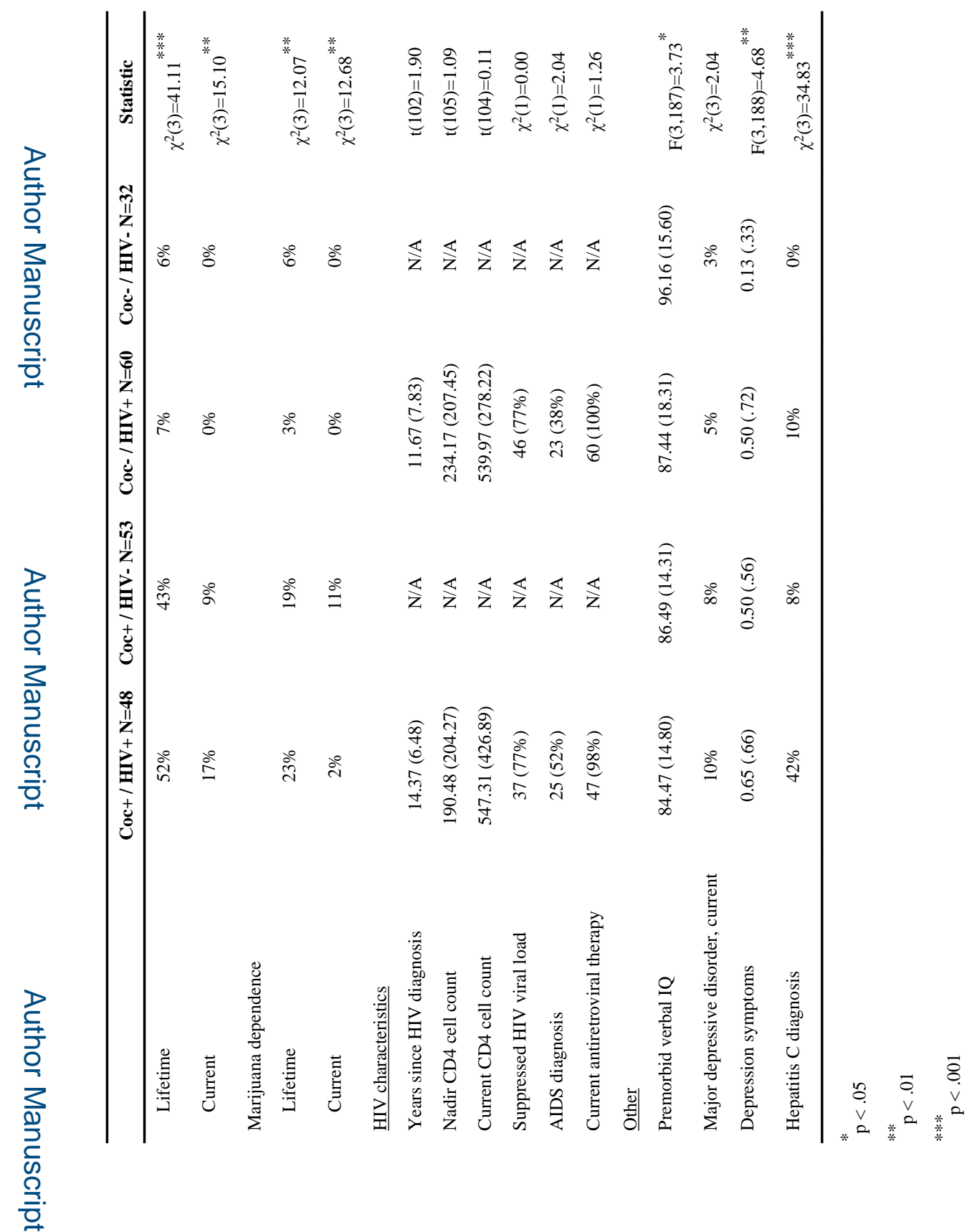

Drug Alcohol Depend. Author manuscript; available in PMC 2016 April 01. 


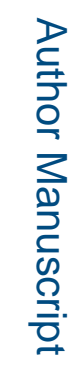

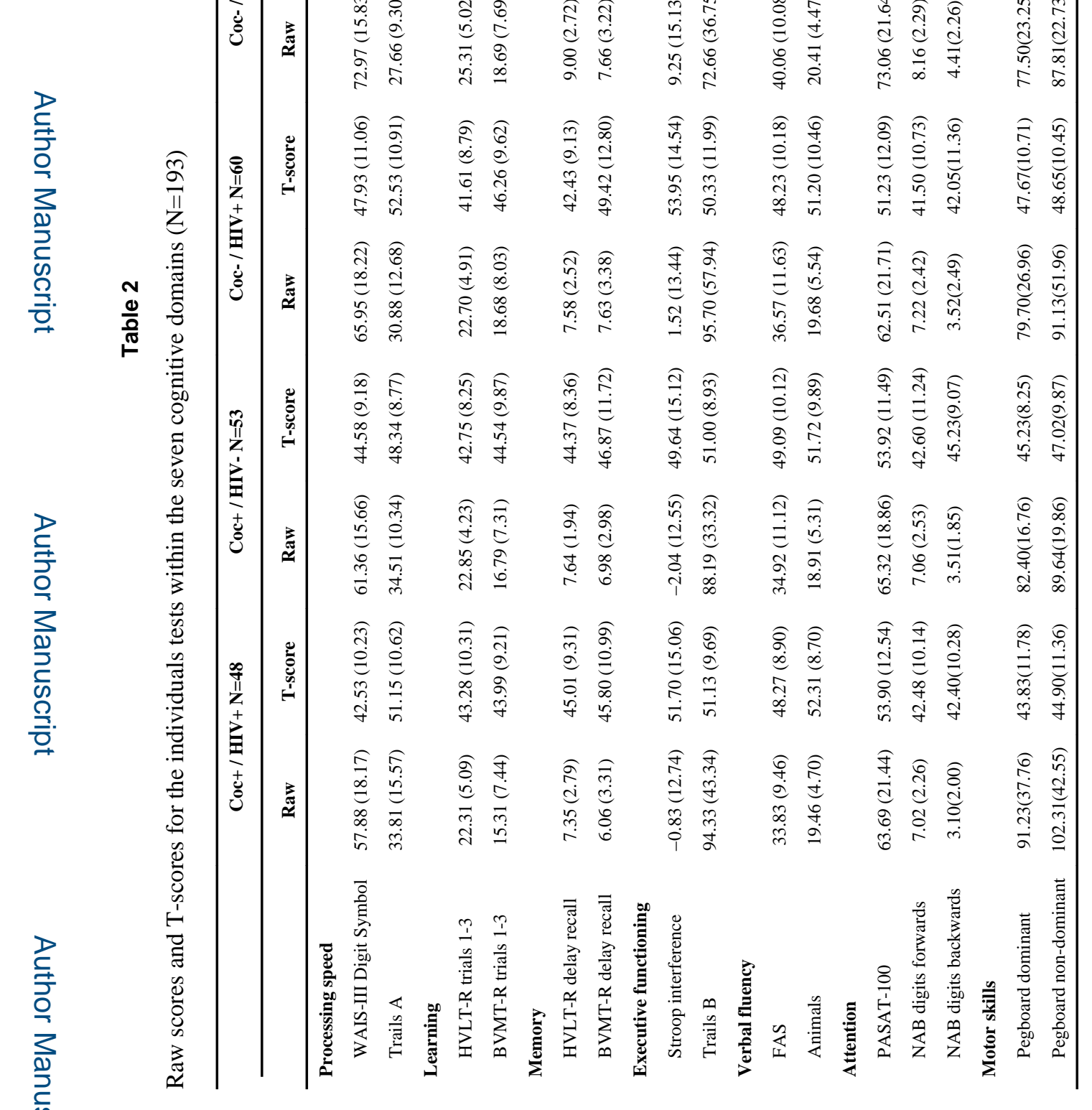

Drug Alcohol Depend. Author manuscript; available in PMC 2016 April 01. 


\section{로을}

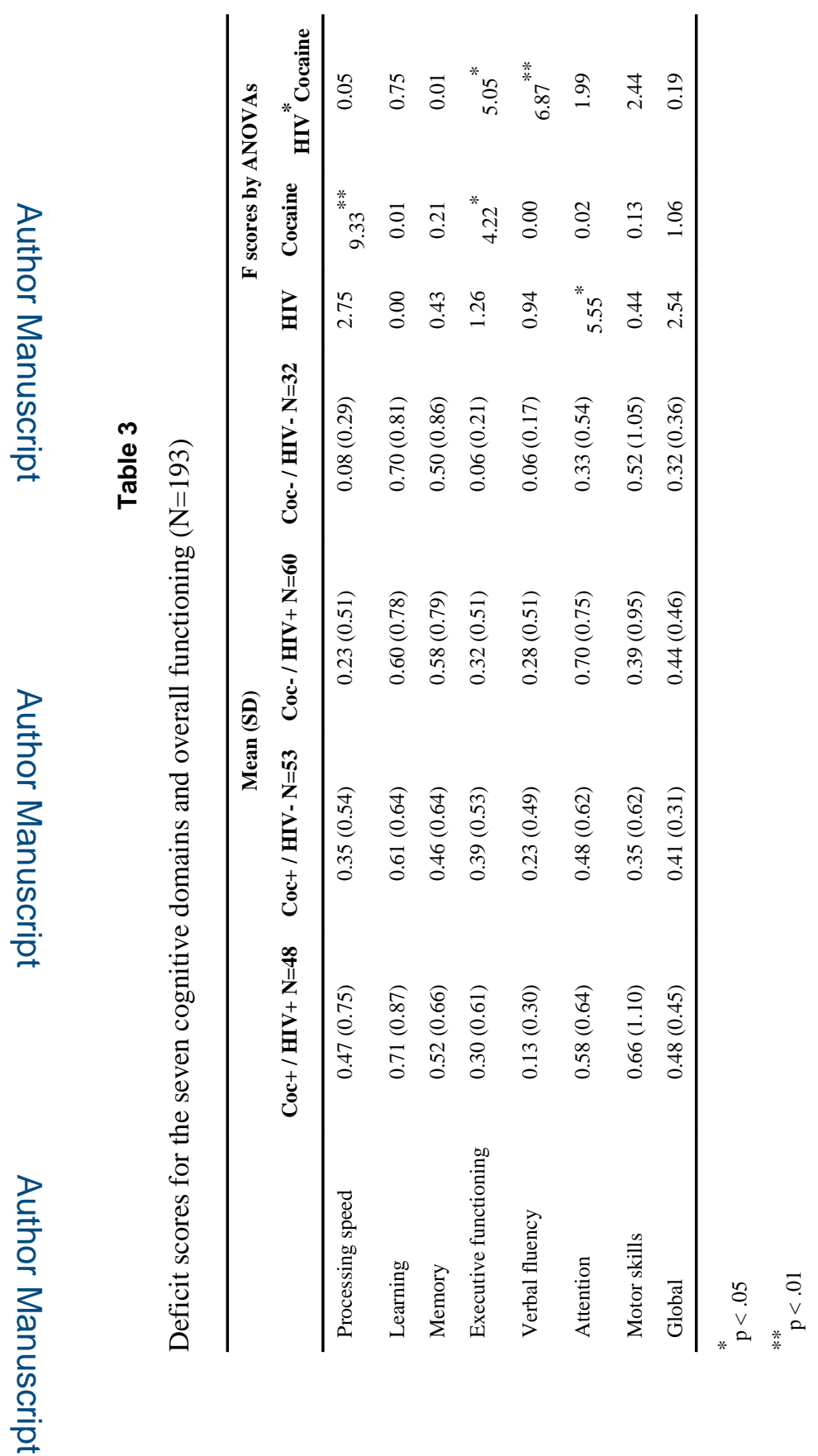

Drug Alcohol Depend. Author manuscript; available in PMC 2016 April 01. 